18

\title{
The Interaction of CdSe/ZnS Quantum Dot with Plasmonic Ag Nanoparticles Deposited on Amorphous Hydrogenated Carbon Thin Films*
}

(C) D. Khmelevskaya, D.P. Shcherbinin, E.A. Konshina, M.M. Abboud, A. Dubavik, and I.A. Gladskikh

ITMO University,

197101 St. Petersburg, Russia

e-mail: khmelevskaya.dasha@yandex.ru

Received July 6, 2018

Local fields of metal nanoparticles can change quantum dots (QDs) absorption and luminescence. In this work, we have investigated the interaction of granulated $\mathrm{Ag} \mathrm{NPs}$ films with $\mathrm{CdSe} / \mathrm{ZnS}$ semiconductor QDs in hybrid structure with $a-\mathrm{C}: \mathrm{H}$ thin films. We have studied hybrid structure with two $a-\mathrm{C}: \mathrm{H}$ films on a quartz substrate having wider optical gap of $2.1 \mathrm{eV}$ and narrow gap of $0.7 \mathrm{eV}$. The distribution of Ag NPs on the $a-\mathrm{C}: \mathrm{H}$ was more ordered unlike a pure quartz surface. Homogeneous films of Ag NPs on $a-\mathrm{C}: \mathrm{H}$ surface have narrower picks of LSPR in spectra. The intensity magnifying and the blue shift of the LSPR peak of Ag NPs on $31 \mathrm{~nm}$ in the spectra has been observed with an increase in the optical gap of $a-\mathrm{C}: \mathrm{H}$ film. We have also compared how the properties of $a-\mathrm{C}: \mathrm{H}$ films in hybrid structures with $\mathrm{Ag}$ NPs affect the absorption and luminescence of $\mathrm{CdSe} / \mathrm{ZnS}$ quantum dots. The absorption maximum for the QDs on Ag NPs/a-C:H surface was higher than on Ag NPs on pure quartz. The red shift of the absorption peak was observed. We have observed photoluminescence quenching of the $\mathrm{CdSe} / \mathrm{ZnS}$ QDs on the surfaces of the studied hybrid structures. The greatest quenching of QD luminescence was observed on quartz substrate. A less significant quenching of the CdSe/ZnS QDs luminescence was obtained in the sample with $a-\mathrm{C}: \mathrm{H}$ film having a wider optical gap.

DOI: $10.21883 /$ OS.2018.11.46834.223-18

\footnotetext{
* International Conference „PCNSPA 2018 - Photonic Colloidal Nanostructures: Synthesis, Properties, and Applications“, Saint Petersburg, Russia, June 4-8, 2018.

Полный текст статьи опубликован в английской версии журнала.
} 